Bond University

Research Repository

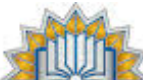 \\ *** BOND \\ UNIVERSITY
}

\section{Piloting mobile mixed reality simulation in paramedic distance education}

Birt, James; Moore, Emma; Cowling, Michael A.

Published in:

2017 IEEE 5th International Conference on Serious Games and Applications for Health, SeGAH 2017

DOI:

10.1109/SeGAH.2017.7939270

Licence:

CC BY-NC-SA

Link to output in Bond University research repository.

Recommended citation(APA):

Birt, J., Moore, E., \& Cowling, M. A. (2017). Piloting mobile mixed reality simulation in paramedic distance education. In N. Rodrigues, J. L. Vilaca, N. Dias, K. Wong, S. de Freitas, \& D. Duque (Eds.), 2017 IEEE 5th International Conference on Serious Games and Applications for Health, SeGAH 2017: Serious Games and Applications for Health (SeGAH) [7939270] (IEEE International Conference on Serious Games and Applications for Health). IEEE, Institute of Electrical and Electronics Engineers. https://doi.org/10.1109/SeGAH.2017.7939270

\section{General rights}

Copyright and moral rights for the publications made accessible in the public portal are retained by the authors and/or other copyright owners and it is a condition of accessing publications that users recognise and abide by the legal requirements associated with these rights.

For more information, or if you believe that this document breaches copyright, please contact the Bond University research repository coordinator 


\section{Bond University}

\section{ePublications@bond}

Faculty of Society and Design Publications

Faculty of Society and Design

2017

\section{Piloting mobile mixed reality simulation in paramedic distance education}

James Birt

Bond University, james_birt@bond.edu.au

Emma Moore

Central Queensland University

Michael A. Cowling

Central Queensland University

Follow this and additional works at: http://epublications.bond.edu.au/fsd_papers

Part of the Communication Technology and New Media Commons, and the Health Communication Commons

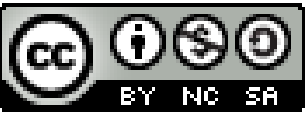

This work is licensed under a Creative Commons Attribution-Noncommercial-Share Alike 4.0 License.

\section{Recommended Citation}

Birt, J., Moore, E., \& Cowling, M. A. (2017). Piloting mobile mixed reality simulation in paramedic distance education. Retrieved from http://dx.doi.org/10.1109/SeGAH.2017.7939270

This Conference Proceeding is brought to you by the Faculty of Society and Design at ePublications@bond. It has been accepted for inclusion in Faculty of Society and Design Publications by an authorized administrator of ePublications@bond. For more information, please contact Bond

University's Repository Coordinator. 


\section{Piloting Mobile Mixed Reality Simulation in Paramedic Distance Education}

\author{
James Birt \\ Faculty of Society and Design \\ Bond University \\ Gold Coast, Australia \\ jbirt@bond.edu.au
}

\author{
Emma Moore \\ School of Medical and Applied \\ Science \\ CQUniversity \\ Rockhampton, Australia \\ e.moore@cqu.edu.au
}

\author{
Michael A. Cowling \\ School of Engineering and \\ Technology \\ CQUniversity \\ Brisbane, Australia \\ m.cowling@cqu.edu.au
}

\begin{abstract}
New pedagogical methods delivered through mobile mixed reality (via a user-supplied mobile phone incorporating 3d printing and augmented reality) are becoming possible in distance education, shifting pedagogy from 2D images, words and videos to interactive simulations and immersive mobile skill training environments. This paper presents insights from the implementation and testing of a mobile mixed reality intervention in an Australian distance paramedic science classroom. The context of this mobile simulation study is skills acquisition in airways management focusing on direct laryngoscopy with foreign body removal. The intervention aims to assist distance education learners in practicing skills prior to attending mandatory residential schools and helps build a baseline equality between those students that study face to face and those at a distance. Outcomes from the pilot study showed improvements in several key performance indicators in the distance learners, but also demonstrated problems to overcome in the pedagogical method.
\end{abstract}

Keywords—mixed reality; mobile learning; augmented reality; $3 d$ printing; distance education; paramedic science;

\section{INTRODUCTION}

In recent years, higher education $[1,2]$ and the health professions $[3,4]$ have seen a shift away from traditional education practice of face to face didactic lectures and tutorials to self-directed online distance education. This is especially true for paramedic science in Australia [5, 6]. This shift in pedagogy towards self-directed distance education causes equality issues between face to face students and those studying remotely especially in regards to skills training.

Twenty-first century students have vocalized readiness for creative new technology led pedagogy and for universities practicing a skills-based approach [7]. However, universities in general are lagging in innovative pedagogy especially when students are studying from a distance, with most prior work formed around $2 \mathrm{~d}$ words and pictures, and less attention given to complex skills learning environments using interactive visualizations, games and simulations [8].

Of particular importance to the health profession is airways management, where inadequate skill and poor judgment can quickly lead to patient complications and death [9]. Airways management education and hands-on training builds essential skills for all health professionals [10] especially for trainee paramedics in pre emergency care [11]. High priority invasive skills such as Direct Laryngoscopy with Foreign body removal requires confidence and experience to execute correctly and benefits improve with hands on skills training.

In health education there is growing, significant evidence that simulation improves learner's competence and skills when compared to traditional didactic methods and or no simulation training $[12,13]$. However, a common discussion point across the health simulation education literature, is the concept of simulation fidelity or the degree to which a simulation looks, feels, and acts like a human patient [14]. Most of the simulation pedagogy research indicates a need for high fidelity (realism) in the simulation. However, the perceived need for face to face high fidelity (only) health education simulations, is changing with more research focusing on the methods to enhance simulation: affordability, availability, mobility, engagement and immersion and not just specifics of fidelity [14-17].

To tackle these issues in the wider higher education sector there is growing evidence that emerging technologies such as Augmented Reality (AR), 3D Printing (3DP) and Mobile Bring Your Own Devices (BYOD) are providing major changes and disruption to the way students learn [18]. The availability of low cost professional game engines such as Unity3d (unity3d.com/), and improvements in AR SDKs such as Vuforia (www.vuforia.com) that work on BYOD mobile devices create new opportunities for the use of mobile mixed reality simulations in distance education.

Therefore, the objective of this pilot study is to explore the pedagogical possibilities of a BYOD mobile mixed reality simulation for airways management training. The context for this study is the skills acquisition and retention, of preresidential paramedic students, focusing on Direct Laryngoscopy with Foreign body removal in an Australian distance Paramedic Science course. The project stems from a need, identified through course evaluations, for more opportunity for distance paramedic students to practice skills prior to residential school. Outcomes from the pilot study showed improvements in several key performance indicators in the distance learners, but also demonstrated problems to overcome in the pedagogical method. 


\section{BACKGROUND PROBLEM}

The use of simulation in teaching is a key means of improving learning, skills and outcomes, particularly when the selected discipline supports the development of practical skills [10-17]. Students in the Bachelor of Paramedic Science program are expected to have developed the real-world expertise and skills to work as health professionals in emergency medicine and retrieval. Graduates of the program anticipate career options with the government ambulance service, private emergency services or in industry providing paramedic services to mine sites and other areas, and graduates employed in this capacity are eligible for membership with Paramedics Australasia and/or the Australian Registry of Emergency Medical Technicians (AREMT). Yet, despite these very practical requirements, the ability to practice practical skills in the program can be limited for many of the students, who study the program at a distance.

This project stems from a need, identified through course evaluations, for more opportunity for distance students to practice skills (currently, they can only be practiced in the fiveday residential schools). An anonymous sample of the comments made by students in course evaluations is provided for study context:

"I believe that because this course is a 'skills' learning course, that there should be a way for us to actually get more time doing skills. I feel that as distance students we are at a severe disadvantage because we spend 5 days doing them in the middle of term and then don't do them again until we hit our placement"

"There is no substitution for experience. Could the school look into either some kind of software or equipment that we could be supplied with so that we can at least go through the motions of doing the skills?"

"I believe that my confidence in performing the procedures and skills could have been improved with a little more 'hands-on' time."

"I feel as an external that I am missing out - they do scenarios every week, I did one or two during res school"

"Studying by distance you can read the skills and kinda do scenarios but it's hard to get feedback and to know if what you're doing is still right."

These issues highlighted by the distance learners are managed to some extent by the program coordinator and course coordinators through intensive residential schools that teach practical skills over the course of a week, as well as work integrated clinical courses in the 2 nd and 3rd year of the program and the encouragement of students to volunteer for the St John's Ambulance service. However, especially for the second-year courses such as the skills development courses, more opportunities for practical skill development is required for paramedic distance education students $[5,6]$.

Discussions between the authors and the paramedics discipline leader were hence focused on what skill could be recreated through a mobile BYOD mixed reality simulation approach and provide the most benefit to the students. This proved to be difficult as most of the skills are non-invasive and have multiple stages which would be difficult to translate into a simulation process. In the end, the key elements of the simulation learning experience were linked to the Australian, Queensland State Ambulance Service Airways Management Clinical Practice Procedures [19] and explored the following key skills:

(1) Direct laryngoscopy (Large adult - using Macintosh Blade Size 4): the technique used to achieve optimal visualisation of the glottis for the purpose of oral endotracheal tube insertion or removal of a foreign $\operatorname{body}($ p. 342)

(2) Magill forceps: removal of pharyngeal foreign bodies causing airways obstruction in an obtunded patient (p. 354)

These skills were chosen as they only use two medical tools (Laryngoscope with Macintosh blade size 4 and Magill Forceps) and are classed as high priority invasive skills. Foreign body removal is a skill that requires confidence and experience to execute correctly, and given that the discipline expert reported that Paramedics do not perform this skill on road very often, it became obvious that this intervention could produce positive learner results.

\section{SimUlation DESIGN}

The context of the simulation was a Direct Laryngoscopy procedure with Magill Forceps foreign body removal as outlined by the Australian Queensland Ambulance Service [19]. The aim was to provide distance paramedic students a haptic, visual and auditory feedback mechanic to assist in learning and practicing the airway skills in line with simulation fidelity research [12-17].

To assist in immersion and accuracy the simulation utilizes three-dimensionally printed representations of the Laryngoscope, Macintosh Blade (size 4) and Magill forceps that are $3 \mathrm{~d}$ modelled on a 1-1 scale (see figure 1 ).

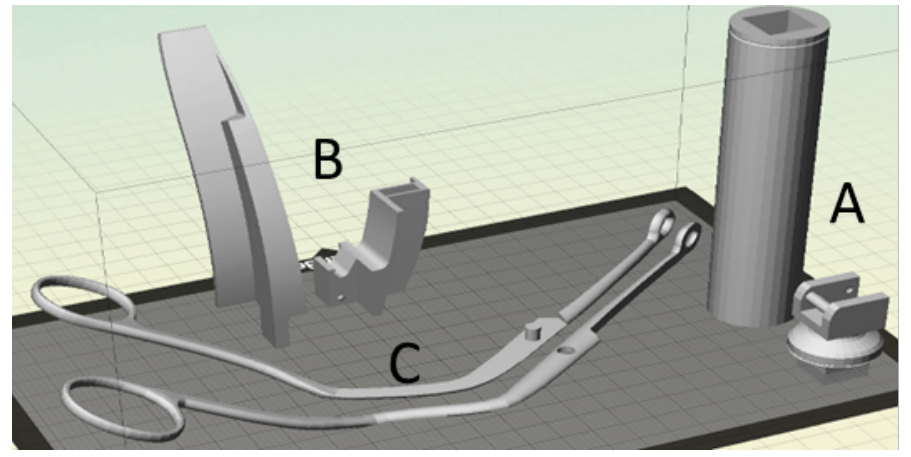

Fig. 1. 3d models representing (a) laryngoscope, (b) macintosh blade size 4 and (c) magill forceps

The aim was to allow objects to print on low cost PLA small print bed size $3 \mathrm{~d}$ printers which resulted in the Macintosh Blade and Laryngoscope being split into two parts to provide increased printer accessibility and allow optional small weights to be added. These realistic physical representations allow for a user's perception to be primed before they carry out the simulation through haptic and visual connection to the tools. 


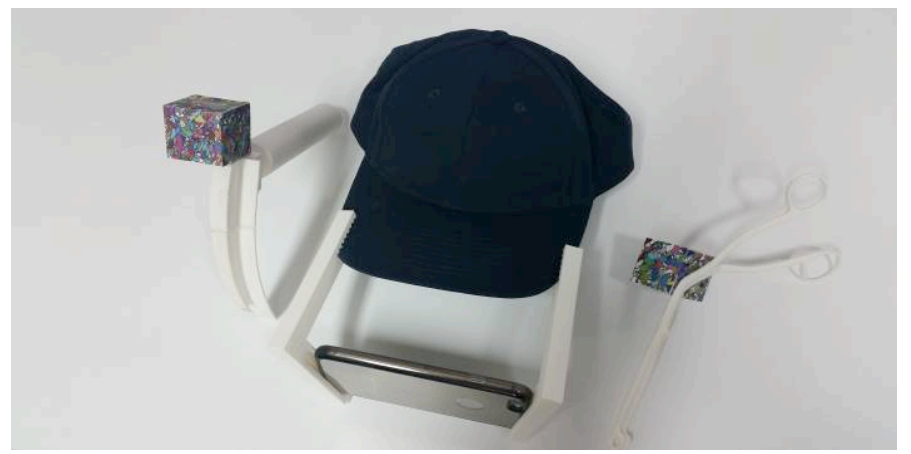

Fig. 2. 3d printed laryngoscope, macintosh blade and magill forceps with augmented reality image targets including hat mounted mobile phone

The use of realistic physical analogs for the tools also enabled the distance learner to become familiar with the actual medical tools they must use, at a fraction of the cost of their real counterparts, while allowing them to be accessible to being $3 \mathrm{~d}$ printed from any location. Through the addition of the Augmented Reality image target markers, these physical models can be tracked and simulated in the mobile simulation environment (see figure 2).

The simulation proposed in the study requires the use of both hands to practice and execute the skills. To allow the learner's hands to be free throughout the simulation their BYOD smart phone needs to be mounted in a hands-free fashion in front of the user's face. It was proposed for the initial study that this be achieved through a pair of $3 \mathrm{~d}$ printed holders that clasp onto the bill of a cap worn on the learner's head (see figure 2). This method of $3 \mathrm{~d}$ printing holders was in attempt to keep aligned with the objective of making the simulation (along with all the required peripherals) easy to access from any location that had an internet connection and $3 \mathrm{D}$ printer, allowing the user to simply print them off and attach them to a cap at home. It also allows for the correct view point, looking down the throat of the airway manikin.

For the augmented reality simulation, the decision was made to use the game engine development platform Unity3d, (Unity Technologies, San Francisco, CA) and Vuforia AR plugin for Unity3d (PTC, Inc). This software is primarily designed for working with object-oriented, multimedia game content and provides a rapid means for deployment to multiple operating systems and mobile device platforms. For the simulation, each tool had an augmented reality maker attached to them for tracking purposes. The AR markers used on the simulation were six sided $3 \mathrm{~cm} \times 3 \mathrm{~cm} \times 3 \mathrm{~cm}$ cubes, which allowed the tools to be tracked from any orientation, so long as one of the sides was visible to the device's camera. This type of tracking utilized Vuforia's MultiTarget marker prefab within Unity3d. The abstract pattern used for the background of the markers was generated by the Augmented Reality Marker Generator by Brovision (http://www.brosvision.com/armarker-generator/).

The focus of the simulation to be task appropriate [14-17] meant that only the pertinent information relating to the key learning outcomes was included. For the developed simulation this refers to only the key indications from the Australian, Queensland Ambulance Service Airways Management Guide
[19] - see Figure 3 for $2 d$ images. The simulation starts with the virtual patient presented at the end of the Triple airways maneuver: patient's head is in the appropriate position to align the oral, pharyngeal and laryngeal axes (p. 343 - figure 3a). For our simulation, only the virtual head is presented to the user reducing processing load on the BYOD mobile phone (see figure $4 \mathrm{a}$ ). The simulation follows a set simulation procedure in line with Direct Laryngoscopy and Foreign Body removal using the Macintosh Blade (Size 4) and the use of the Magill Forceps as follows:

Step1: Grip the laryngoscope handle with the left hand in a position to ensure optimal control and mechanical advantage (p. 343 - figure 3b). The simulation detects the laryngoscope using the image recognition application and instantiates (presents) a virtual $3 \mathrm{~d}$ model of the laryngoscope at 1:1 scale (figure $4 \mathrm{~b}$ ) shown in yellow, triggering step 2. If at any time the user incorrectly positions the instrument(s) in the green colliders it presents a red guide. The user has a few seconds to correct the mistake before the simulation restarts.

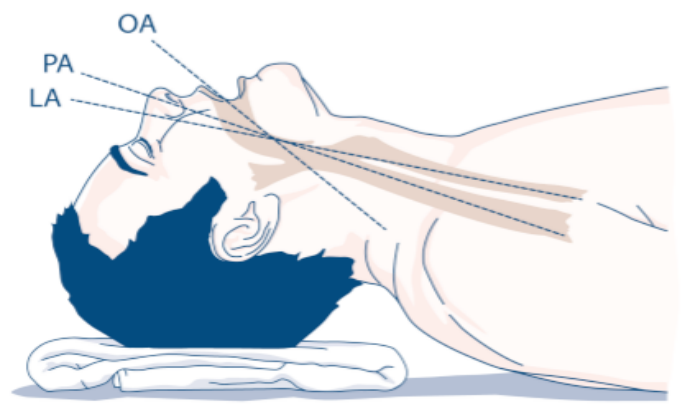

(a) patient position after a tripple airways maneuver

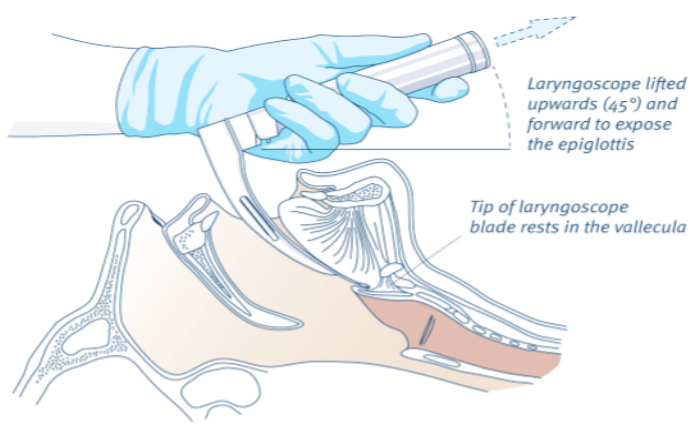

(b) direct larangoscopy procedure

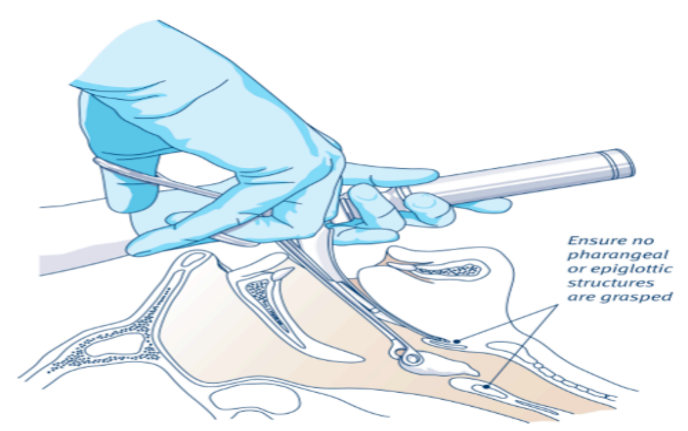

(c) foreign body removal procedure

Fig. 3. $2 \mathrm{~d}$ approach to educate direct larangoscopy with foreign body removal 


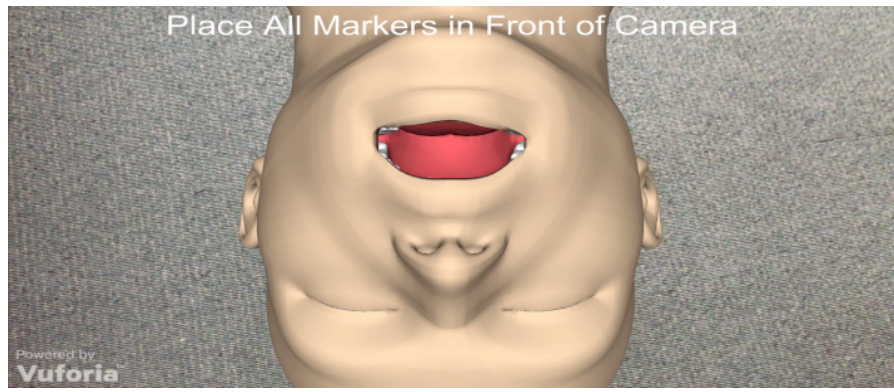

(a) Virtual patient at end of the triple airways maneuver

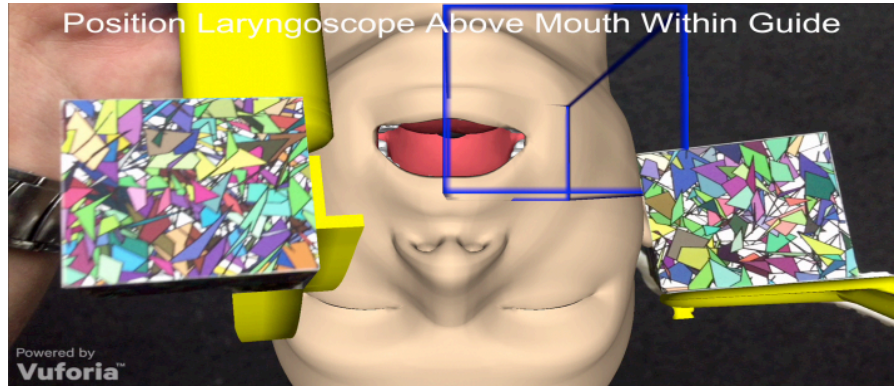

(b) $3 d$ printed tools tracked with virtual objects

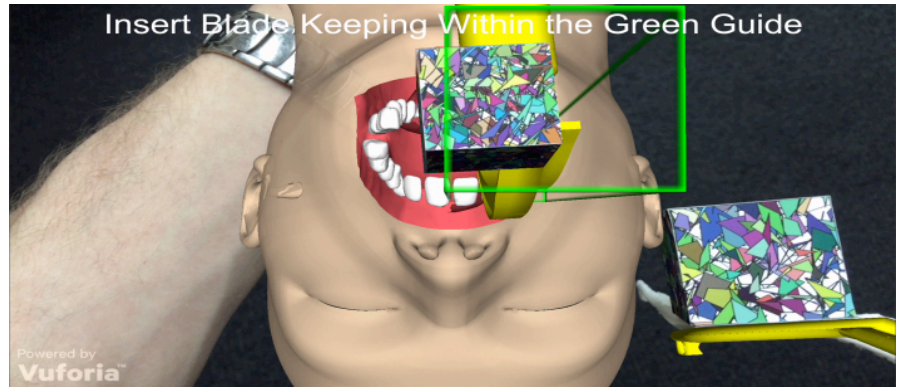

(c) Insertion of larangascope in right side of patient mouth

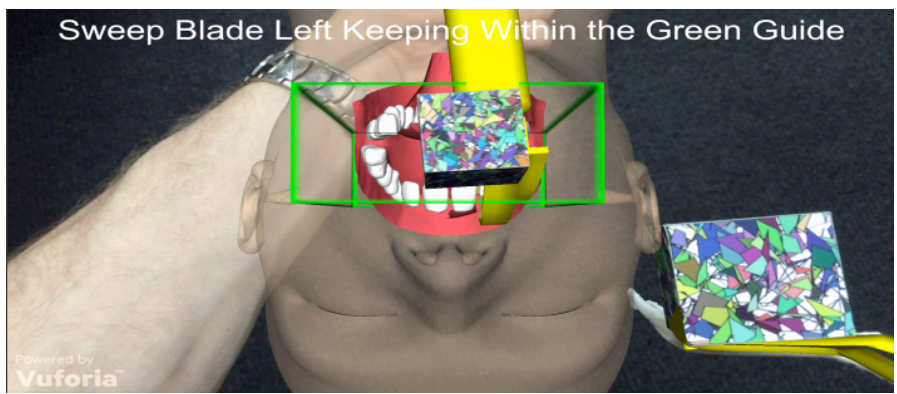

(d) Lateral left sweep of larangscope

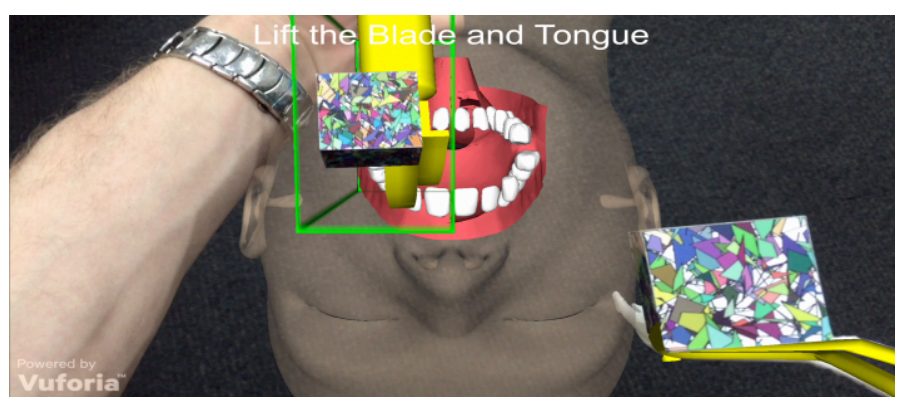

(e) Tongue lift with view of anatomy and foreign body

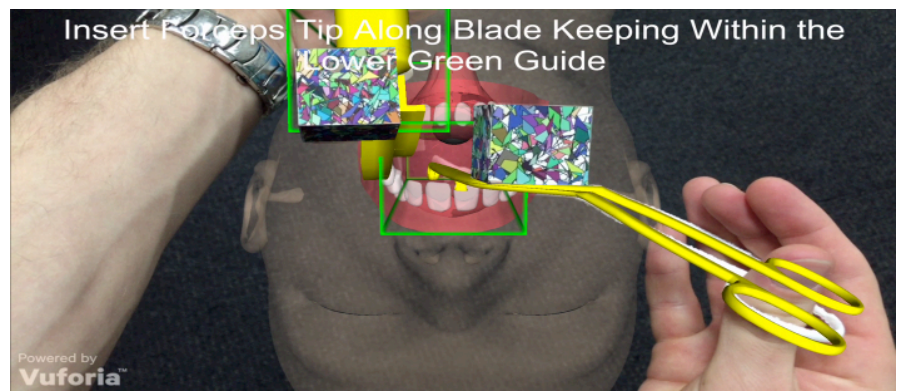

(f) Magill forceps tracking, insertion and gripping process

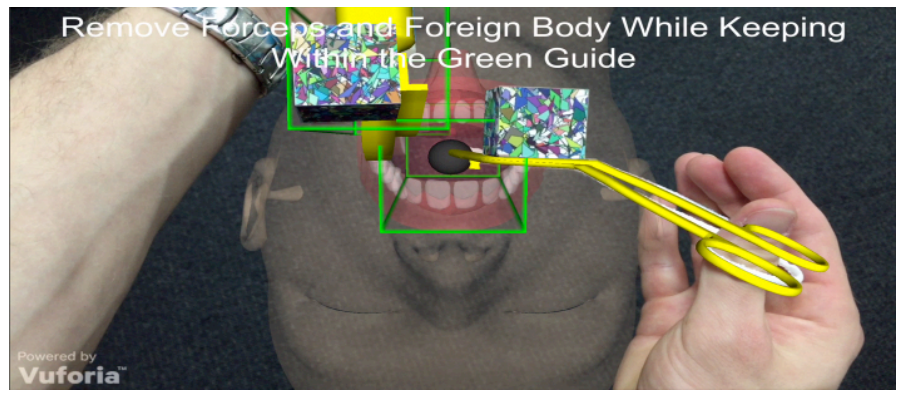

(g) removal of magill forceps including foreign body and laryngoscope

Fig. 4. Simulation of direct larangoscopy with foreign body removal

Step2: Place the [Macintosh Blade] into the right side of the patient's mouth (p. 343 - figure 3b). The simulation detects the correct path of the laryngoscope (figure $4 \mathrm{c}$ ) and if correct triggers step 3 .

Step3: Gently sweep the tongue to the left and position the [Macintosh Blade] midline in the mouth (p. 343 - figure 3b). The simulation detects the correct lateral path of the laryngoscope (figure $4 \mathrm{~d}$ ) and if correct triggers step 4.

Step4: Move the [Macintosh Blade] progressively down the tongue identifying relevant anatomy. Gently place the top of the [Macintosh Blade] in the vallecular. Lift upwards and forward at a $45^{\circ}$ angle to expose the epiglottis (p. 343 - figure $3 \mathrm{~b})$. The simulation detects the correct path and angle of the laryngoscope (figure 4e) and if correct triggers step 5. In the simulation image, you will see that the virtual patient head has become semi-transparent offering the learner a clear view of the anatomy and foreign body. A Grade 1 Cormack-Lehane airways classification (p. 345) has been used for the simulation.

Step5: Grasp the forceps in the right hand with the thumb and ring finger inserted into the holes. Ensure correct grasp of laryngoscope prior to insertion. Insert forceps into the patient's mouth (closed). Under direct laryngoscopy, open and close the Magill forceps to grasp the object. Manipulate the object as required - ensure no pharyngeal or epiglottic structures are grasped (p. 355 - figure 3c). The simulation detects the Magill forceps and tracks the insertion and gripping process (figure 4f) if correct triggers step 6 . The guide turns red if it detects any touching of the forceps on the patient's throat or if the laryngoscope is moved.

Step6: Instrument Removal. The simulation detects the correct removal and angle of removal of both the Magill Forceps including Foreign Body and Laryngoscope (figure 4g). 


\section{RESEARCH METHOD}

The experiment involved an independent groups design. The independent variable was the presence or absence of the simulation detailed previously. The dependent variable was the overall score received on four (4) key performance indicators.

All $2^{\text {nd }}$ year distance paramedic students were invited to participate $(N=85)$ with a stratified sample of 30 students selected from the cohort to receive the $3 \mathrm{~d}$ printed instruments and access to the augmented reality simulation. These students were given instructions on how to use the tools and encouraged to practice for one week prior to the residential school scheduled for late in the term. The final participants were ( $N=64$ female:35, male:29), including those that received the simulation $(N=27$ female: 14 , male:13) and those that did not receive the simulation ( $N=37$ female:21, male: 16$)$.

All students in the study were pre-tested before the residential school on four (4) separate key performance indicators across the two selected airways skills, including whether they:

(1) placed the laryngoscope in the right side before performing a lateral sweep;

(2) elevated the laryngoscope without levering of the teeth;

(3) adequately visualized the obstruction and safely removed it;

(4) removed the laryngoscope without damaging structures.

Participants either passed or failed each key performance indicator which was awarded a score of 1 or 0 , respectively. Performance on all tasks were combined and assessed collectively with each participant receiving a score ranging from 0 (failed all four key performance indicators) to 4 (passed all four key performance indicators).

The traditional "hands on" training was provided to all students in the residential school, with an intermediate post skills test conducted after this training. For ethics compliance, all students not selected for the trial were given extra training using the $3 \mathrm{~d}$ printed tools and augmented reality application after the post test. Data collected from the skills test was analyzed using SPSS to determine correlations and crosstabulations between the two groups. Observations of the learners use of the simulation by the lead paramedic and observation team during residential school was recorded to assist with usability and ongoing simulation pedagogy design.

\section{RESUlts}

During pre-testing participants exposed to the simulation received higher scores on their overall key performance indicators $($ Mean $=2.22 ;$ Median $=3.00 ; S D=1.48 ;$ Mean Std. Error $=0.28)$ than did participants who were not exposed to the simulation $($ Mean $=1.89 ;$ Median $=2.00 ; S D=1.51 ;$ Mean Std. Error $=0.25)$. As demonstrated in Table 1, the majority $(62.2 \%)$ of participants who were not exposed to the simulation failed 2 or more key performance indicators. Conversely, the majority
(51.9\%) of participants who were exposed to the simulation passed 3 or more of the key performance indicators.

TABLE I. PERFORMANCE SCORES IN PARTICIPANTS WHO WERE AND WERE NOT EXPOSED TO THE SIMULATION

\begin{tabular}{|c|c|c|}
\hline Performance Score & No Simulation & Simulation \\
\hline 0 & $11(29.7 \%)$ & $6(22.2 \%)$ \\
\hline 1 & $3(8.1 \%)$ & $2(7.4 \%)$ \\
\hline 2 & $9(24.3 \%)$ & $5(18.5 \%)$ \\
\hline 3 & $7(18.9 \%)$ & $8(29.6 \%)$ \\
\hline 4 & $7(18.9 \%)$ & $6(22.2 \%)$ \\
\hline$n$ & $37(100 \%)$ & $27(100 \%)$ \\
\hline
\end{tabular}

a. Note. Percentages were calculated with respect to independent simulation groups.

An alpha level of .05 was used for all statistical tests, but an independent samples t-test of overall performance found no significant difference on the participants task performance when comparing those who were and were not exposed to a simulation of those tasks beforehand, $\mathrm{t}(62)=-0.874, \mathrm{p}=.385$.

Given this lack of significant difference, each individual skill observation was then examined showing the KPI difference between the groups (see Table 2). When observed placing the laryngoscope in the right side before performing a lateral sweep, $14(52 \%)$ of learners that received the simulation passed compared with $15(41 \%)$ of learners that did not receive the simulation. When observed elevating the laryngoscope without levering of the teeth $12(44 \%)$ of learners that received the simulation passed compared with $11(30 \%)$ of learners that did not receive the simulation. When observed adequately visualizing the obstruction and safely removing it $16(59 \%)$ of learners that received the simulation passed compared with 21 $(57 \%)$ of learners that did not receive the simulation. When observed removing the laryngoscope without damaging structures, $18(67 \%)$ of learners that received the simulation passed compared with $23(62 \%)$ of learners that did not receive the simulation.

TABLE II. INDIVIDUAL SKILL OBSERVATIONS IN PARTICIPANTS WHO WERE AND WERE NOT EXPOSED TO THE SIMULATION

\begin{tabular}{|c|c|c|c|c|c|}
\hline \multirow{2}{*}{ KPI } & Group & $\mathbf{N}$ & Mean & Std. Deviation & $\begin{array}{c}\text { Std. Error } \\
\text { Mean }\end{array}$ \\
\hline \multirow{2}{*}{1} & No Simulation & 37 & .41 & .498 & .082 \\
\cline { 2 - 6 } & Simulation & 27 & .52 & .509 & .098 \\
\hline \multirow{2}{*}{2} & No Simulation & 37 & .30 & .463 & .076 \\
\cline { 2 - 6 } & Simulation & 27 & .44 & .506 & .097 \\
\hline \multirow{2}{*}{3} & No Simulation & 37 & .57 & .502 & .083 \\
\cline { 2 - 6 } & Simulation & 27 & .59 & .501 & .096 \\
\hline \multirow{2}{*}{4} & No Simulation & 37 & .62 & .492 & .081 \\
\cline { 2 - 7 } & Simulation & 27 & .67 & .480 & .092 \\
\hline
\end{tabular}


It must be noted that all learners passed in post testing after the completion of the residential school. Indicating no negative impact of the simulation tool on the learners.

In regards to the observational data, the intervention was observed by the lead paramedic in the study including discussions with the students and other paramedics involved in the residential school. Observations from the lead paramedic are highlighted in the discussion below:

\section{"[Learners] were very excited to get the chance to try this new technology and [the learners] found it great to be able to receive their [simulation] and practice the skills at home. It helped [the learner] feel more involved in the course and less isolated and alone.}

When the $3 d$ printed tools and augmented reality [simulation] were used by the [learner] the [observers] found most [learners] struggled with the setup of the equipment and progression through the required steps. This was especially prevalent in the later steps when introducing the Magill forceps and removing the foreign body. The [learners] commented "there needs to be more depth in the simulation" my hands seem to pass by the [simulated airways manikin]. The [learners] commented that they spent too much time focusing on the markers and not on the [simulated airways manikin] resulting in frustration when the simulation would present red boxed and restart.

Many of the [learners] commented that they did not get around to using the [simulation] as much as they would have liked, with most only having a week to practice before residential school. This time struggle was because of other studies, work and family commitments.

On reflection [I] should have encouraged more frequent use of the simulation with a reminder and linkage to the learning tasks. In regards to integration of the [simulation] into the course this has been relatively seamless. Students are excited to experience a new mode of learning; however, some [learners] seem to think it may be "extra work" for them. With regards to the current simulation introducing more haptic resistance feedback during the insertion and reducing the setup struggle will assist. Additionally, there needs to be a redesign of the markers as they distract from the simulation process."

\section{DISCUSSIONS}

The results of this study reveal some useful insights that highlight distance learner improvement in several key performance indicators and observations of the simulation tool that can be used to facilitate the simulation improvement for ongoing use.

The mobile mixed reality simulation has shown improvement in several key performance skills when compared to no simulation use which is consistent with the health and airways management simulation literature [10-17]. Although these results were not statistically significant it does highlight the growing support for lower fidelity and higher available simulation tools in health education [14-17]. It also supports the ongoing research and application of AR, BYOD and 3D printing into higher education pedagogy in line with Johnson et al. [18] and Ayres [8] research on the need to explore complex skills learning environments using interactive visualizations, games and simulations and not just on $2 \mathrm{~d}$ images and text.

The work shows that getting students to use the technology is not difficult, with many students eager to practice the skills at home and excited to try new technology. This is consistent with reported findings of Bennett, et al. [7] in their discussion on how students use technology. By making the learner feel more involved in the course and less isolated and alone the simulation technology can act as an icebreaker giving a common discussion between the students.

The work does however compound on the struggle of distance education learners especially in paramedic science [5, 6 ] in Australia with students commenting on competing time commitments and the simulation being extra work. It also highlights the pedagogy does have a significant way to come before it does become mainstream in distance education with the simulation not significantly outperforming the no simulation group, being a struggle to setup, issues in simulation progression and problems with the overall visualization and haptic feedback. Regarding these comments, it is suggested that future implementations of the simulation will include a data analytics component that will record the time spent in the simulation, the outcomes of the attempts (successful or not) linking this back to the learner and teaching staff allowing for early intervention and usability assessment. Building greater adoption and a sense of positive use of the simulation.

Specifically, addressing these issues around the simulation, with this type of head mount being used, a normal (nonstereoscopic) image was depicted on the device's screen. It was found that this representation of the $3 \mathrm{~d}$ objects in the virtual environment lead to a slight dissonance in regards to the learners sense of depth and their hands occluding the virtual airways patient. This was because a $3 \mathrm{~d}$ environment of which the learner had to physically interact within was being presented in a $2 \mathrm{~d}$ format as a video feed behind the $3 \mathrm{~d}$ objects. This was particularly evident when a learner went to interact with the virtual objects in the scene (such as inserting the forceps down into the throat of the virtual head) as they could not accurately tell how far objects were in relation to one another. This dissonance in combination with the found fragility and encumbrance of the 3D printed mounts calls for an adjustment in regards to the ease-of-use and way in which the virtual environment is presented to the user. Future versions of the simulation will use a stereoscopic image and headset based on the Google Cardboard design which still allows for a costeffective BYOD solution and should help to reduce these problems.

Regarding the AR markers, the cube markers presented two main problems. The first was that the size of each AR individual marker (each face of the cube) was too small and presented tracking problems resulting in learner frustration and 
some issues with the completion of the simulation. It is recommended that the minimum size of a marker be the maximum distance between it and the device's camera divided by

(https://developer.vuforia.com/library/articles/Best_Practices/R ecommendations-for-Improving-Target-Detection-and-

Tracking-Stability ). In the case of this simulation that would equate to roughly an arm length of $60 \mathrm{~cm}$ divided by 10 , leaving the recommended minimum at $6 \mathrm{~cm}^{2}$ for the marker size which would compound the issues as seen in figure 4, with the markers obscuring the observer's visual presentation and leading to more issues on the learners focusing on the marker and not on the instruments and patient anatomy. It is recommended in future trials to use larger image markers but transition the user from an augmented reality view to a virtual reality view using the AR view to situate and link the user to the task and world but focusing and eliminating the issued around the marker occlusion and marker focus problems.

The material upon which the AR markers were printed also had a significant effect on the performance of tracking by a device's camera. Reflective surfaces, such as glossy papers and inks, would reflect light into the camera, obscuring sections of each marker. This can be combated by printing the markers on Polypropylene, which has a flat matte finish, and almost no light reflection but does add to the cost of the simulation process.

Regarding the haptic resistance feedback, the simulation will require an additional feedback simulating the feeling of the patient's throat. By reducing the visual marker issues, it is suggested that a marker be placed on a cut back $3 \mathrm{~d}$ printed airways manikin head simulating the resistance and guidance of the throat and allowing a mounting position for the airways AR marker reducing the sensation of the airways manikin floating in space.

Finally, the simulation has only focused on the indications from the Australian, Queensland Ambulance Service Airways Management Guide [19] and a Grade 1 Cormack-Lehane airways classification (p. 345) for the two focused skills future work will need to explore the complications and contraindications of these skills.

\section{CONCLUSIONS}

This paper has presented results from a pilot study involving a mobile BYOD mixed reality simulation using $3 \mathrm{~d}$ printed physical objects and Augmented Reality simulation to help with distance paramedic education skills development in airways management. The focus of the study was on improving pre-residential skills in direct laryngoscopy with foreign body removal and helping to bridge the hands-on learning gap between distance students and those in a face to face learning modality.

Results from the study showed that the learners improved in several key performance indicators in pre-residential school observation and that learners found the mixed reality simulation exciting to use. However, it also highlighted problems with the pedagogy method and improvements that need to be made before the method can become statistically useful in health education skills training.

Future work will involve moving from indications only to include contraindications and complications and working on the simulation issues around the stereoscopic image, marker occlusion and transitioning the view from AR to virtual reality and improving the issues around marker pickup and haptic resistance.

Through this work, a greater understanding on the use of innovative technology tools and mixed reality BYOD simulation in distance education will be obtained, proving foundations for future research.

\section{REFERENCES}

[1] R. C. Clark and R. E. Mayer, E-learning and the science of instruction: Proven guidelines for consumers and designers of multimedia learning: John Wiley \& Sons, 2016.

[2] M. G. Moore and G. Kearsley, Distance education: A systems view of online learning: Cengage Learning, 2011.

[3] D. A. Cook, A. J. Levinson, S. Garside, D. M. Dupras, P. J. Erwin, and V. M. Montori, "Instructional design variations in internet-based learning for health professions education: a systematic review and meta-analysis," Academic Medicine, vol. 85, pp. 909-922, 2010.

[4] M. H. Murad, F. Coto-Yglesias, P. Varkey, L. J. Prokop, and A. L. Murad, "The effectiveness of self-directed learning in health professions education: a systematic review," Medical education, vol. 44, pp. 1057-1068, 2010.

[5] X. Y. Hou, J. Rego, and M. Service, "Review article: paramedic education opportunities and challenges in Australia," Emergency Medicine Australasia, vol. 25, pp. 114-119, 2013.

[6] B. Williams, M. Boyle, A. Molloy, R. Brightwell, G. Munro, and T. Brown, "Undergraduate paramedic students' attitudes to e-learning: findings from five university programs," Research in Learning Technology, vol. 19, 2011.

[7] D. Bennett, S. Richardson, and P. MacKinnon, "Enacting strategies for graduate employability: How universities can best support students to develop generic skills," Sydney: Australian Government Office for Learning and Teaching, 2015.

[8] P. Ayres, "State-of-the-Art Research into Multimedia Learning: A Commentary on Mayer's Handbook of Multimedia Learning," Applied Cognitive Psychology, vol. 29, pp. 631-636, 2015.

[9] J. Williamson, R. Webb, A. Sellen, W. Runciman, and J. Van der Walt, "The Australian Incident Monitoring Study. Human failure: an analysis of 2000 incident reports," Anaesthesia and intensive care, vol. 21, pp. 678-683, 1993. 
[10] P. Baker, J. Weller, K. Greenland, R. Riley, and A. Merry, "Education in airway management," Anaesthesia, vol. 66, pp. 101-111, 2011.

[11] M. Aziz, D. Dillman, J. R. Kirsch, and A. Brambrink, "Video laryngoscopy with the macintosh video laryngoscope in simulated prehospital scenarios by paramedic students," Prehospital Emergency Care, vol. 13, pp. 251-255, 2009.

[12] D. A. Cook, R. Brydges, S. J. Hamstra, B. Zendejas, J. H. Szostek, A. T. Wang, et al., "Comparative effectiveness of technology-enhanced simulation versus other instructional methods: a systematic review and meta-analysis," Simulation in Healthcare, vol. 7, pp. 308-320, 2012.

[13] W. C. McGaghie, S. B. Issenberg, E. R. Petrusa, and R. J. Scalese, "A critical review of simulation-based medical education research: 2003-2009," Medical education, vol. 44, pp. 50-63, 2010.

[14] S. J. Hamstra, R. Brydges, R. Hatala, B. Zendejas, and D. A. Cook, "Reconsidering fidelity in simulation-based training," Academic Medicine, vol. 89, pp. 387-392, 2014.

[15] D. A. Cook, S. J. Hamstra, R. Brydges, B. Zendejas, J. H. Szostek, A. T. Wang, et al., "Comparative effectiveness of instructional design features in simulation-based education: systematic review and meta-analysis," Medical teacher, vol. 35, pp. e867e898, 2013.

[16] G. Norman, K. Dore, and L. Grierson, "The minimal relationship between simulation fidelity and transfer of learning," Medical education, vol. 46, pp. 636-647, 2012.

[17] B. Zendejas, A. T. Wang, R. Brydges, S. J. Hamstra, and D. A. Cook, "Cost: the missing outcome in simulation-based medical education research: a systematic review," Surgery, vol. 153, pp. 160-176, 2013.

[18] L. Johnson, Adams Becker, S., Cummins, M., Estrada, V., Freeman, A., and Hall, C., "NMC Horizon Report: 2016 Higher Education Edition.," Austin, Texas, 2016.

[19] C. Q. P. S. Unit, "Clinical Practice Procedures: Airway Management," Queensland Ambulance Service, 2016. 